\title{
Başkonuş Mesire Yeri'nden (Kahramanmaraş) Sağlanan Ekosistem Hizmetlerine Yönelik Algının İncelenmesi
}

\author{
Hakan DOYGUN ${ }^{1 *}$, Dilay ZÜLKADİROĞLU², Ilgaz EKŞS ${ }^{3}$
}

\section{ÖZ}

Bu çalışma ile, Başkonuş mesire yerinden (Kahramanmaraş) sağlanan ekosistem hizmetlerine yönelik algının Q metodoloji yardımıyla incelenmesi amaçlanmıştır. Katılımcılar tarafından yapılan değerlendirmeler sonucunda koruma ve doğallık odaklı olmak üzere iki bakış açısı ortaya çıkmıştır. Katılımcıların çoğunluğu mesire yerinin yaşam konforu üzerindeki olumlu etkilerine değinmişler, ancak bazen yoğunlaşabilen rekreasyonel faaliyetlerin sükûnet ortamını ve doğal çevreyi olumsuz etkilediğini de belirtmişlerdir. Bu doğrultuda; mesire yeri ziyaretçi taşıma kapasitesinin hesaplanması, rekreasyonel kullanımların sınırlandırılması ve alanın doğal şekli ile kalabilmesi için yapısal düzenlemelerden olabildiğince kaçınılması önerilmektedir. Çalışma ile elde edilen sonuçların mesire yerinde gerçekleştirilecek uygulamalara, Q metodoloji ve ekosistem hizmetleri konulu literatüre katkı sağlaması beklenmektedir.

Anahtar kelimeler: Başkonuş mesire yeri; Q metodoloji, ekosistem hizmetleri; Kahramanmaraş.

\section{Investigation of Perception on Ecosystem Services Provided from Başkonuş Recreation Area (Kahramanmaraş)}

\begin{abstract}
With this study, it is aimed to examine the perception on ecosystem services provided from Başkonuş recreation area (Kahramanmaraş) by using Q methodology. As a result of the evaluations made by the participant group, two perspectives, one focused on protection and the other on naturalness, emerged. Most of the participants mentioned the positive effects of the recreation area on the comfort of life, but they also stated that the recreational activities sometimes may negatively affect the tranquility and the natural environment. It is recommended that visitor carrying capacity of the recreation area should be calculated, the recreational uses should be limited, structural arrangements should be avoided as much as possible in order to keep the area in its natural form. The results of the study are expected to contribute to the practices to be carried out in the recreation area and the literature on Q methodology and ecosystem services.
\end{abstract}

Keywords: Başkonuş recreation area; Q methodology; ecosystem services; Kahramanmaraş

ORCID ID (Yazar sirasına göre)

0000-0003-2920-1984, 0000-0002-5466-9207, 0000-0002-5466-9207

Yayın Kuruluna Geliş Tarihi: 16.05.2021

Kabul Tarihi: 03.12.2021

${ }^{1}$ İzmir Demokrasi Üniversitesi Mimarlık Fakültesi Peyzaj Mimarlığı Bölümü, İzmir.

${ }^{2}$ Çukurova Üniversitesi Fen Bilimleri Enstitüsü Peyzaj Mimarlığı Anabilim Dalı, Adana.

${ }^{3}$ İzmir Demokrasi Fen Bilimleri Enstitüsü Peyzaj Mimarlığı Anabilim Dalı, İzmir.

*E-posta: hakan.doygun@idu.edu.tr 


\section{Başkonuş Mesire Yeri’nden (Kahramanmaraş) Sağlanan Ekosistem Hizmetlerine Yönelik Algının İncelenmesi}

\section{Giriş}

İnsan refahının ve çoğu ekonomik faaliyetin dayanağını meydana getiren ekosistemler doğanın işleyişini, bileşenlerini ve bileşenler arasındaki etkileşimleri kapsamakta olup, ekosistem hizmetleri de insanların doğadan sağladıkları yararları ifade etmektedir (TEEB Foundations, 2010; MEA 2005a). Ekosistem hizmetleri, doğal kaynakların yönetim stratejilerini değerlendirmek için politika oluşturmada (Breure et al., 2012) ve alan kullanım planlama çalıșmalarını desteklemede (Niemela et al., 2010) etkin rol oynama potansiyeline sahiptir. Bu doğrultuda, ekosistem hizmetlerinin söz konusu süreçlere veri olarak dahil edilebilmeleri için ölçülebilir niteliklerle ifade edilmeleri gerekmekte, bu ihtiyaca yönelik olarak da ekosistemlerin ve sundukları hizmetlerin ekolojik, ekonomik ve sosyokültürel bakımlardan değerlendirilmelerini öngören yaklaşımlar bulunmaktadır (De Groot et al., 2010a; Jobstvogt et al., 2014; Çiftçioğlu ve Aydın, 2018).

Ekolojik değer bir sistemin çeşitlilik ve bütünlük bakımından sağlik durumunu yansitırken ekonomik ve sosyo-kültürel değerler o sisteme insanların yüklediği göreceli önemi ortaya koymakta, sosyo-kültürel yaklaşım atfettiği önemi para ile ifade etmeyerek ekonomik değerleme biçiminden ayrılmaktadır (De Groot et al., 2010b; Scholte et al., 2015). Sosyokültürel değerleme yöntemi konuya yönelik farkındalık oluşturma, ayrışmaları tanımlama ve öncelik belirleme yoluyla farklı seslerin ve paydaşların karar alma sürecine dahil edilmesine yardımc1 olmakta (Santos-Martin, et al., 2017), ayrıca ekosistem servislerine yönelik tercihlerin anlaşılmasını da sağlamaktadır (Martin-Lopez et al., 2012). Bu açıdan bakıldığında, ilk defa fizikçi William Stephenson tarafindan 1935 y1lında ortaya atılan Q metodoloji (Stephenson, 1935; Brown, 1993); belirli gruplar nezdinde tercih edilen, paylaşılan veya farklılaşan bakış açıları ile öncelikleri ortaya koymada, insan öznelliğini belirlemede etkin olarak yararlanılan bir sosyo-kültürel değerleme yaklaşımıdır (Brown, 1980; Gauger and Wyckoff, 1973; Watts and Stenner, 2005; Maniatakou et al., 2020). Bilimsel araştırmalarda çok farklı alanlarda giderek yaygınlaşan biçimde kullanılmaya başlanan Q metodoloji; hava kirliliği (Sala et al., 2015), enerji (Cuppen et al., 2010), iklim değișikliği (Zivojinovic and Wolfslehner, 2015), orman yönetimi (Steelman and Maguire, 1999), kırsal çalışmalar (Hermans et al., 2011) ve tarım (Alexander et al., 2018) gibi konularda grupların bakış açılarını belirlemede araştırmacılara yeni bakış açıları sunmakta; ayrica parklardan (Buchel and Frantzeskaki, 2015), ormanlardan (Çiftçioğlu, 2020), sulak alanlardan (Maniatakou et al., 2020), denizel çevrelerden (Pike et al., 2015) veya akarsulardan (Kerr and Swaffield, 2012) sağlanan ekosistem hizmetlerine yönelik alg1 ve tercihlerin belirlenmesinde de önemli rol oynamaktadır.

Bu çalıșmada, Kahramanmaraș İli'nde bulunan Başkonuş mesire yerinden sağlanan ekosistem hizmetlerine yönelik algının Q metodoloji yardımıyla incelenmesi amaçlanmıştır. Yoğun bir orman dokusu içerisinde bulunması ve çeşitli kullanım olanaklarını bünyesinde barındırması nedeniyle, bir rekreasyon alanı olarak yöre halkının Başkonuş mesire yerine olan ilgisi giderek artmaktadır. Bu çalışma ile elde edilen sonuçların, Başkonuş mesire yerine yönelik yapılacak iyileştirme ve geliştirme uygulamalarına, Q metodoloji ve ekosistem hizmetleri üzerine gerçekleștirilecek benzer araştırmalara yön göstermesi beklenmektedir.

\section{Materyal ve Yöntem Araştırma alanı}

16 ha yüzölçümüne sahip Başkonuş mesire yeri Türkiye'nin Doğu Akdeniz Bölgesi'nde Kahramanmaraş İli sınırları içerisinde bulunan Başkonuş Dağı'nın 1300 m yükseltilerinde, Kahramanmaraş kentine $55 \mathrm{~km}$ mesafede yer almaktadır (Şekil 1). Zengin bir floraya sahip olan Başkonuş Dağ 1 55'i endemik 528 taksona ev sahipliği yapmakta (Varol, 2003), mesire yerini kapsayan Yediardıç mevkii de önemli sayıda endemik türü bünyesinde barındırmaktadır (Koçyiğit ve Kayıran, 2018). Başkonuş Dağ ve mesire yeri genelinde hakim türler Pinus brutia (Kızılçam), Pinus nigra (Karaçam), Cedrus libani (Lübnan sediri), Abies cilicica (Toros göknarı), Quercus cerris (Saçl1 meşe) olarak belirlenebilmektedir (Anonim, 2011; Karakoç ve Karabulut, 2017). Mesire 


\section{Başkonuş Mesire Yeri’nden (Kahramanmaraş) Sağlanan Ekosistem Hizmetlerine Yönelik Algının İncelenmesi}

alanına yakın konumdaki Andırın İlçesi meteorolojik verilerine göre y1llık ortalama sicaklık $13{ }^{\circ} \mathrm{C}$ olup ortalama en düşük ve en yüksek sicaklıklar Ocak $\left(3.2{ }^{\circ} \mathrm{C}\right)$ ve Ağustos $\left(22.9^{\circ} \mathrm{C}\right)$ aylarında görülmektedir (Sandal, 2017).

Zengin bitki örtüsü, serin iklimi ve karayolu ile rahat ulaşım imkanı bulunması nedeniyle Kahramanmaraş başta olmak üzere çevre kentlerden çok sayıda ziyaretçinin yıl boyunca geldiği Başkonuş mesire yeri arazilerinde ilk olarak 1987 y1lında 4 ha arazide Kizil Geyik (Cervus elaphus) üretim istasyonu kurulmuş, 1995 yılında ise B tipi Orman İçi Dinlenme Yeri olarak halkın kullanımına açılmıştır. 2006 yılından itibaren A tipi mesire yeri olarak tescil edilen alanda Mayıs-Eylül ayları arasını kapsayan yaz sezonunda günlük gelen araç sayıs1 200'ü, ziyaretçi say1s1 da 1000'i geçebilmektedir (Karakoç ve Karabulut, 2017). Mesire yerinde trekking, doğa fotoğrafçılığı, ateşsiz piknik gibi günübirlik faaliyetler gerçekleştirilebilmekte, yöresel doğal ürünlere mesire alanında ve çevresinde ulaşmak mümkün olmakta, ayrıca çadır, karavan ve orman evlerinde konaklama imkanı bulunmaktadır. Başkonuş mesire yerinin iklimi ve ormanlık yapısının insan sağlığını destekleyici niteliğinden yararlanmak amaciyla y1l boyu olabilen uzun süreli konaklamalar ziyaretçiler tarafindan tercih edilen faaliyetler arasında yer almaktadır.
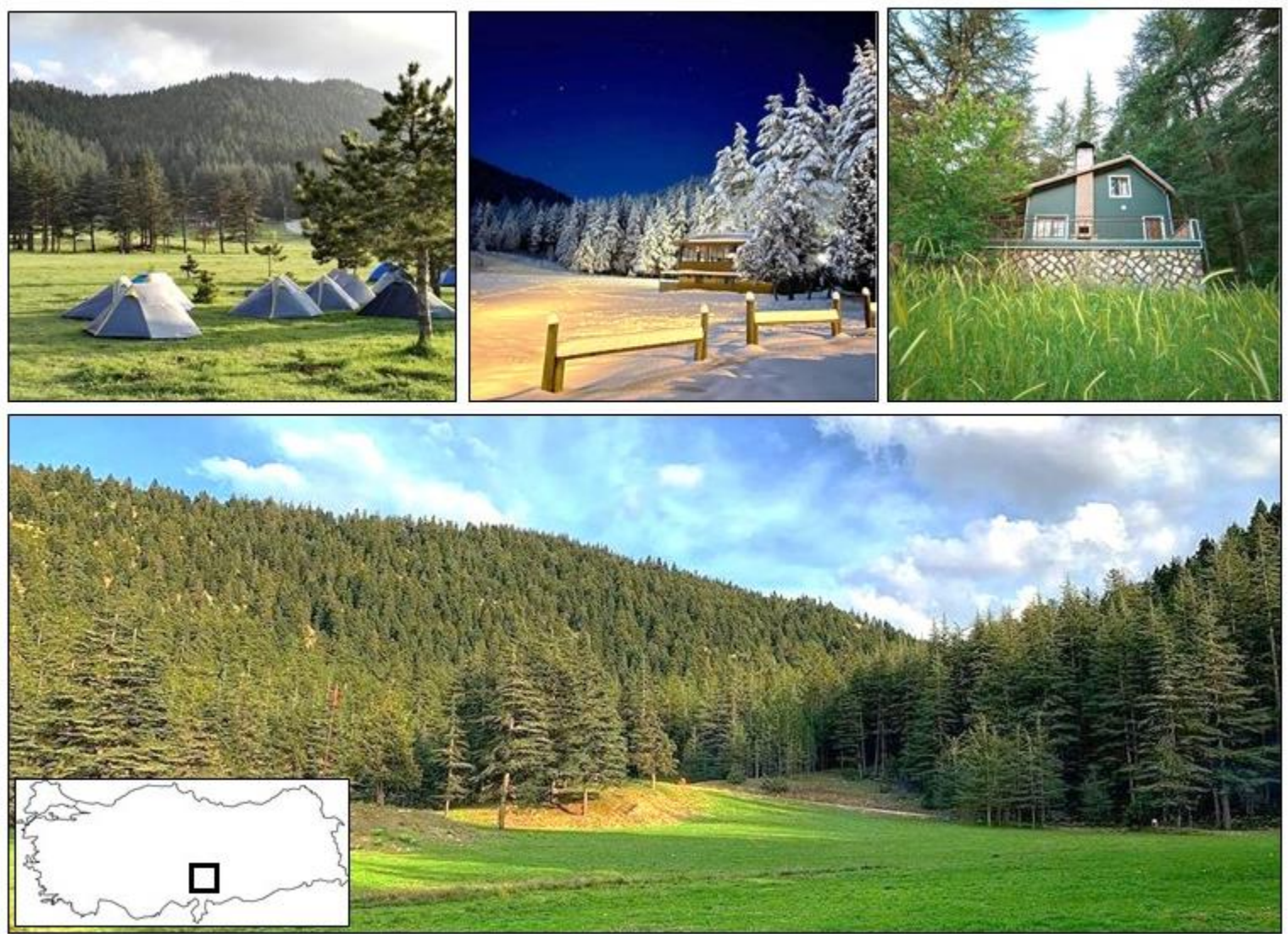

Şekil 1. Başkonuş mesire yerine ait görünümler (Başkonuş Yaylası, 2021).

\section{Yöntem}

$\mathrm{Bu}$ çalışmanın yöntemi, Başkonuş mesire yerinden sağlanan ekosistem hizmetlerine yönelik kullanıcı algısının incelenmesi doğrultusunda başlıca beş aşamadan meydana gelmektedir (Şekil 2). Birinci aşamada, katılımcıların konu ile ilgili algılarının ve bakış açılarının ortaya konulmasında büyük öneme sahip olan ifadeler geliştirilmiştir. Bir Q metodoloji çalıșmasında, ifadelerin araştırılan konu hakkındaki görüşleri geniş ölçüde temsil etmesi beklenmekte, bunu sağlamak için de 


\section{Başkonuş Mesire Yeri’nden (Kahramanmaraş) Sağlanan Ekosistem Hizmetlerine Yönelik Algının İncelenmesi}

bilimsel kaynaklardan, bas1lı ve görsel medyadan, konu hakkında bilgi sahibi kişilerle yapılan görüşmelerden, pilot çalışmalardan veya bunların kombinasyonlarından yararlanılması önerilmektedir (Watts and Stenner, 2005). Başkonuş mesire yeri için gerçekleştirilen bu çalışmada söz konusu yaklaşımlar bir arada kullanılmış, ifadelerin geliştirilmesinde öncelikle alan hakkında bilgiye sahip kişilerle görüşmeler yapılmıştır. Uzmanlar (Mesire yeri işletmecisi, Peyzaj Mimarları, Mimarlar, Orman Mühendisleri, Ziraat Mühendisleri, Çevre Mühendisleri) ile diğer eğitim ve meslek gruplarından meydana gelen bu kişilere "Başkonuş mesire yerini tercih etme nedenleri, mesire yerinden sağladıklarl faydalar ve mesire yeri ile ilgili olumsuz buldukları konular" sorulmuş, sonuç olarak bir dizi ifadeye ulaşılmıştır. Bu ifadeler arasında benzer olanlar eşleştirilerek sadeleştirmeye gidilmiş, daha sonra Millenium Ecosystem Assessment (MEA, 2005b) çalışmasından da yararlanılarak gözden geçirilen ifadeler dört ana başlık altında gruplara ayrılmıştır (Tedarik Hizmetleri, Düzenleyici Hizmetler, Destekleyici Hizmetler, Kültürel Hizmetler).

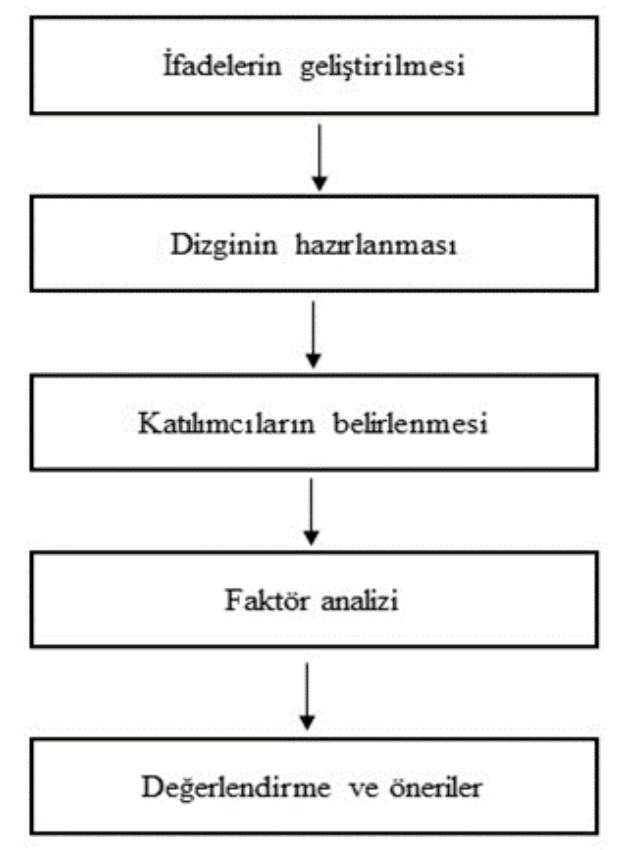

Şekil 2. Çalışma akış şeması.

Bir Q metodoloji çalışmasında konu hakkındaki görüşlerin geniş ölçüde temsil edilmesi gerektiğinden hareketle (Watts and Stenner, 2005), karşit fikirlerin de savunulabilmesine olanak tanınması bakımından ifadeler arasında olumsuz cümle yapılarının da bulunması sağlanmalı, ancak bu durum, aynı görüşe ait iki zit kutup izlenimi oluşturmamalıdır (Amin, 2000). Bu çalışmada da ifadeler arasında olumsuz cümle yapılarının bulunmasına dikkat edilmiş, ardından bir ön çalışma gerçekleştirilerek bütün ifadeler açıklık, ifade bozukluğu, gereksiz olup olmama gibi açılardan incelenmek üzere mesire yeri hakkında bilgi sahibi olan, ancak ilk ifadelerin hazırlanma sürecinde yer almamış bir diğer grubun görüşüne sunulmuştur (Watts ve Stenner, 2005; Karasu ve Peker, 2019). Bu grubun da önerileri göz önüne alınarak yapılan revizyon sonucunda toplam 34 ifadeye ulaşılmıştır (Q-Set).

Çalışmanın ikinci aşamasında ifadelerin yerleştirileceği dizgi hazırlanmıştır. Bir Q metodoloji çalışmasında katılımcılar konu ile ilgili bakış açılarını ifadelerin dizgi üzerindeki konumları aracılığıyla ortaya koymaktadırlar. $\mathrm{Bu}$ çalışmada zorunlu dağılım yapısında tasarlanan dizgi modeli ile katılımcilar "Katılmiyorum (-4) / Kararsizım (0) / Katılıyorum (+4)" aralığında, ifadeler arasında önceliklendirme yapmaya teşvik edilmekte yani görüşlerin kristalize edilebilmesine olanak sağlanmaktadır (Demir ve Kul, 2011; Karasu ve Peker, 2019) (Şekil 3). Dizgi hazırlandıktan sonra, rastgele numaralandırılarak kutucuklar içerisine yazılan ifadeler ile dizgi bir word dosyasında bir araya getirilmiş, daha sonra katılımın gönüllü olduğunu ve çalışmanın içeriğini belirten bilgilendirme notu ile birlikte katılımcılara iletilmiştir.

Çalışmanın üçüncü aşamasında katılımcılar belirlenmiştir. Q metodoloji uygulamasında çok sayıda katılımcıya ihtiyaç bulunmamakta, araştırılan konu hakkında temel bakış açılarının ortaya çıkarılmasında 40-60 arası katılımcının yeterli olacağı belirtilmektedir (Stainton Rogers, 1995; Watts and Stenner, 2005). Başkonuş mesire yeri için gerçekleştirilen bu çalı̧̧mada katılımcıların tespitinde Snowball (Kartopu) yöntemi benimsenmiştir (Webler et al., 2009). $\mathrm{Bu}$ yöntemde öncelikle araştırılan konu ve/veya alan hakkında bilgi ve deneyim sahibi bir veya birkaç kişi belirlenmekte, daha sonra bu kişilere, 


\section{Başkonuş Mesire Yeri’nden (Kahramanmaraş) Sağlanan Ekosistem Hizmetlerine Yönelik Algının İncelenmesi}

aynı konu hakkında değerlendirme yapabilecek başkalarını önermeleri istenmektedir. $\mathrm{Bu}$ şekilde, kişilerin bir diğerini önermesi prensibine dayalı olarak merkezden dişa doğru gelişen katılımcı grubuna ulaşılmaktadır. $\mathrm{Bu}$ çalışma için söz konusu yöntemle katılımcıların belirlenmesinde, bakış açıları arasındaki olası farklılaşmaları belirleyebilmek amacıyla katılımcıların uzmanlar ile (Peyzaj Mimarı, Orman Mühendisi, Ziraat Mühendisi, Çevre Mühendisi, Mimar, İnşaat Mühendisi) diğer eğitim ve meslek gruplarından karma bir şekilde meydana gelmesine dikkat edilmiş, sonuç olarak, Başkonuş mesire yerinde günübirlik veya uzun süreli çeşitli aktivitelerde bulunmuş, alan hakkında değerlendirme yapabilecek düzeye sahip toplam 53 kişilik katılımeı grubuna ulaşılmıştır (P-Set).

Katılımcılar konuya yönelik bakış açıları doğrultusunda ifadeleri dizgi üzerine yerleştirdikten sonra bu dizgilerin analizi çalışmanın dördüncü aşamasını meydana getirmektedir. Analiz sürecinde PQ Method V
2.35 (Schmolck, 2014) programından yararlanılmıştır. İfadelerin dizgi üzerinde hangi hücrede yer aldığ 1 bilgisi programa manuel olarak girildikten sonra Temel Bileşen Analizi (Principle Component Analysis- PCA) gerçekleştirilmiş, sonuçlar Varimax Rotation ile döndürüldükten sonra ifadelerin dizgi üzerindeki konumları doğrultusunda katılımcıların meydana getirdiği gruplara yani faktörlere ulaşı1mıştır. Analizlerde kaç faktörün söz konusu olabileceği PCA sonucunda ortaya çıkan Eigenvalue (Özdeğer) verisine göre anlaşılabilmekte, döndürme sonrasında elde edilen korelasyon değerleri de faktörler arası bakış açılarının farklılaşma düzeyini göstermektedir. Faktörler arasındaki korelasyon değerleri 1'den uzaklaştıkça grupları meydana getiren katılımcıların bakış açıları arasında farklılıklar olduğu anlaşılmakta, 1'e yaklaştı̆̆ında ise bakış açılarının birbirleri ile yakınlık gösterdiği düşünülmektedir.

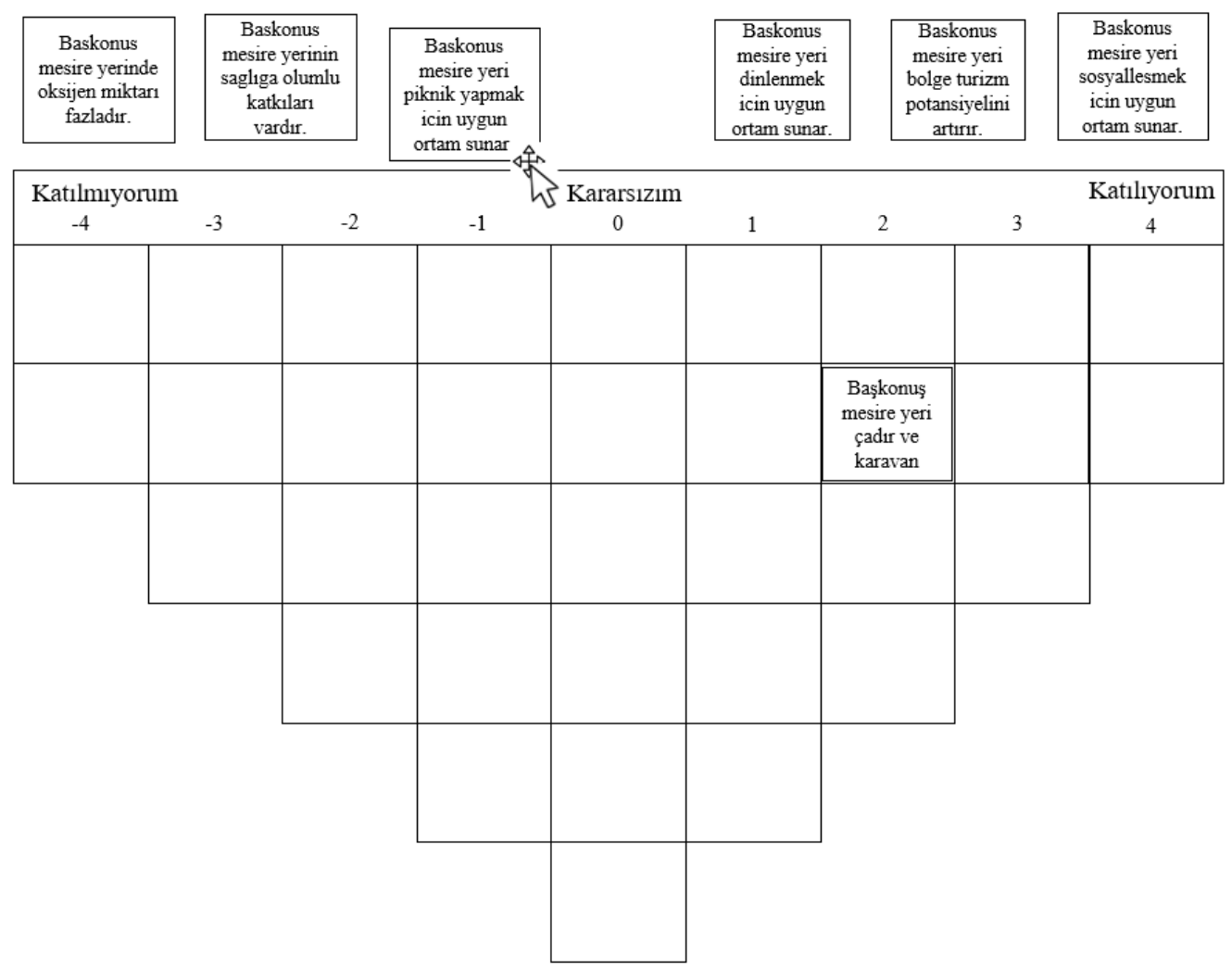

Şekil 3. İfadelerin yerleştirilmesinde kullanılan dizgiye ait bir örnek. 


\section{Başkonuş Mesire Yeri’nden (Kahramanmaraş) Sağlanan Ekosistem Hizmetlerine Yönelik Algının İncelenmesi}

\section{Bulgular ve Tartışma}

Katılımcilar tarafindan ifadeler yerleştirilerek hazırlanan dizgilere PCA uygulanması sonucunda elde edilen Eigenvalue verileri Başkonuş mesire yerinden sağlanan ekosistem hizmetlerine yönelik iki faktörün olabileceğini işaret etmiş, buna ek olarak yapılan iki, üç ve dört faktörlü denemeler de korelasyon değerleri bakımından iki faktörün konuya yönelik yaklaşımları temsil etme düzeyinin daha elverişli olacağını teyit etmiştir.

Katılımc1ların 33'ü 1 nolu faktör grubunu, 6's1 2 nolu faktör grubunu meydana getirmişlerdir. Diğer katılımcılar ise faktör yükleri itibarı ile her iki grupta da varlık göstermeleri veya grupların herhangi birine dahil olmamaları nedeniyle değerlendirme dişında tutulmuşlardır. Faktörlerde yer alan katılımcılar meslek, cinsiyet, eğitim ve yaş grupları bakımından ayrıca incelenmişlerdir (Çizelge 1). Buna göre, 1 nolu faktörde yer alan katılımcılar arasında uzmanlara nazaran (\%42) diğer meslek gruplarının (\%58) ağırlık kazandığı, kadınların (\%51) ve erkeklerin (\%49) eşite yakın biçimde temsil edildikleri, üniversite mezunlarının (\%82) çoğunlukta olduğu, yaş gruplarının ise 25-35 yaş (\%39), 35-45 yaş $(\% 33)$ ve $45<$ yaş $(\% 27)$ sıralaması ile varlık gösterdikleri anlaşılmıştır. 2 nolu faktörde de uzmanlar, kadınlar, üniversite mezunları ve 25-35 yaş aralığı çoğunluğa sahip olmuşlardır.

Çizelge 1. Gruplar bazında katılımcılara ait bilgiler.

\begin{tabular}{|l|c|c|c|c|c|c|c|c|c|}
\hline & \multicolumn{2}{|c|}{ Meslek } & \multicolumn{2}{c|}{ Cinsiyet } & \multicolumn{2}{c|}{ Eğitim } & \multicolumn{3}{c|}{ Yaş } \\
\cline { 2 - 11 } & Uzman & Diğer & Kadın & Erkek & Üniv. & Lise & $25-35$ & $35-45$ & $45<$ \\
\hline 1 nolu grup & 14 & 19 & 17 & 16 & 28 & 5 & 13 & 11 & 9 \\
\hline 2 nolu grup & 4 & 2 & 5 & 1 & 5 & 1 & 3 & 2 & 1 \\
\hline
\end{tabular}

Faktörlerde hangi bakış açılarının ortaya çıktığını belirlemek için ifadelerin faktörler bazındaki sıralama değerlerinden, yani dizgi üzerinde yer aldıkları konum bilgilerinden yararlanılmaktadır. Faktör analizi sonuç çıktılarında "Factor Arrays" adı altında yer alan bilgilerden yararlanılarak Çizelge 2'de ifadelerin dizgi üzerindeki konum bilgileri verilmiş, katılımcıların en çok onay verdikleri ifadeler de ayrıca koyu renk ile işaretlenmiştir.

Q metodoloji çalışmalarında, faktörlerde ön plana çıkan bakış açılarını yansıtmak amacıyla her faktöre isim verilmektedir (Buchel and Frantzeskaki, 2015; Çiftçioğlu, 2020). Aynı kapsamda, Başkonuş mesire yeri için gerçekleştirilen bu çalışmada 1 nolu faktör Koruma ve 2 nolu faktör de Doğallık isimleri ile tanımlanmıştır.

Koruma (1 nolu faktör): Bu faktörü meydana getiren katılımcilar ikisi olumlu ve üçü de olumsuz olmak üzere toplam beş ifade üzerinde önemle durmuşlardır. Katılımcılar "Başkonuş mesire yerinde oksijen miktarl fazladır (+4)" ve "Başkonuş mesire yerinin yaz mevsiminde serinletici etkisi vardir (+3)" ifadeleri ile mesire yerinin yaşam konforunu iyileştirici özelliklerine olumlu vurgu yapmışlardır. Diğer taraftan aynı katılımcılar; ziyaretçi yoğunluğunun doğada olması gereken sükûnet ortamını olumsuz etkilediği (+3), mesire amaçlı kullanımların kirlenmeye, görsel bozulmaya neden olduğu (+3) ve bazı doğal özellikler için risk oluşturduğu (+4) görüşlerine de ön planda yer vererek mesire yerinin korunması ve iyileştirilmesi gereken özelliklerini işaret etmişlerdir.

Koruma' ya yönelik bakış açısının hakim olduğu bu faktördeki katılımcıların öne sürdükleri görüşlerin alan ile ilgili önceki bazı çalışmaların sonuçlarıyla da örtüşüyor olması dikkat çekicidir. Örneğin Karakoç ve Karabulut (2017), daha tenha ve daha doğal ortam arayışında olan bazı ziyaretçilerin herhangi bir tesis veya donanım bulunmamasına rağmen Başkonuş mesire yerine $3 \mathrm{~km}$ mesafedeki bir diğer yayla alanını (Sersem Yayla) tercih ettiklerini belirterek sükûnet konusuna dikkati çekmişlerdir. Diğer taraftan mesire yeri ve çevresinin, belirli türler açısından Başkonuş Dağ 1 genelinde en çok endemik ve nadir taksonları barındırdığı, ancak rekreasyonel kullanımların ve kirlenmenin doğal yap1 


\section{Başkonuş Mesire Yeri’nden (Kahramanmaraş) Sağlanan Ekosistem Hizmetlerine Yönelik Algının İncelenmesi}

üzerinde bask1 oluşturduğu belirtilmektedir (Anonim, 2011; Karakoç ve Karabulut, 2017; Koçyiğit ve Kayıran, 2018).

Doğallkk (2 nolu faktör): Bu faktörü meydana getiren katılımcılar, ön plana çıkardıkları beş olumlu ifade aracılığıyla mesire yeri doğal yapısından kaynaklanan yararlar üzerinde durmuşlardır. Başkonuş mesire yerinin oksijen miktarı (+3) ile serinletici etkisi (+4) bu faktörde de üst suralarda yer bularak her iki faktörün ortak yönlerini meydana getirmişlerdir. Mesire yerinin biyolojik çeşitliliği destekleyen bir yapısı olduğu (+3) 2 nolu faktörde en çok kabûl gören beş ifade arasında yer almaktadır. Yine aynı faktörde, Başkonuş mesire yerinin doğa ile baş başa kalmak (+3) ve dinlenmek (+4) için uygun ortamlar sunduğu yönünde görüş birliği oluşmuştur.

Çizelge 2. Faktörler bazında ifadelerin dizgi üzerindeki konumları.

\begin{tabular}{|c|c|c|}
\hline \multirow[b]{2}{*}{ EKOSİSTEM HİZMETLERİ } & \multicolumn{2}{|c|}{ FAKTÖR } \\
\hline & $\begin{array}{c}1 \\
\text { (Koruma) } \\
\end{array}$ & $\begin{array}{c}2 \\
\text { (Doğallık) } \\
\end{array}$ \\
\hline \multicolumn{3}{|l|}{ Tedarik Hizmetleri } \\
\hline Başkonuş mesire yerinde oksijen miktarı fazladır. & 4 & 3 \\
\hline $\begin{array}{l}\text { Başkonuş mesire yerindeki oksijen miktarı yöredeki diğer benzer yerler ile } \\
\text { aynıdır. }\end{array}$ & -4 & -4 \\
\hline \multicolumn{3}{|l|}{ Düzenleyici Hizmetler } \\
\hline Başkonuş mesire yerinin yaz mevsiminde serinletici etkisi vardır. & 3 & 4 \\
\hline $\begin{array}{l}\text { Yaz mevsiminde Başkonuş mesire yerindeki hava sıcaklığı yöredeki diğer benzer } \\
\text { yerler ile aynıdır. }\end{array}$ & -3 & -4 \\
\hline Başkonuş mesire yerinin sağlığa olumlu katkıları vardır. & 2 & 1 \\
\hline $\begin{array}{l}\text { Başkonuş mesire yerinin sağlığa katkısı alanın diğer faydalarına göre daha geri } \\
\text { plandadır. }\end{array}$ & -3 & -1 \\
\hline \multicolumn{3}{|l|}{ Destekleyici Hizmetler } \\
\hline Başkonuş mesire yeri biyolojik çeşitliliğin korunarak gelişmesi için ortam sağlar. & -1 & 3 \\
\hline Yörenin biyolojik çeşitliliği Başkonuş mesire yeri olmadan da gelişebilir. & -2 & -3 \\
\hline \multicolumn{3}{|l|}{ Kültürel Hizmetler } \\
\hline Başkonuş mesire yeri doğa ile baş başa kalmak icin uygun ortam sunar. & 2 & 3 \\
\hline $\begin{array}{l}\text { Bazı günlerdeki kullanıcı yoğunluğu, Başkonuş mesire yerinin sakin ve huzurlu } \\
\text { ortamını bozmaktadır. }\end{array}$ & 3 & 0 \\
\hline Başkonuş mesire yeri piknik yapmak icin uygun ortam sunar. & 1 & 2 \\
\hline Başkonuş mesire yerinde piknikten başka yapılacak daha güzel aktiviteler vardır. & 2 & -1 \\
\hline Başkonuş mesire yeri çadır ve karavan kamp için uygun ortam sunar. & 1 & 0 \\
\hline $\begin{array}{l}\text { Kamp yapmak Başkonuş mesire yeri için geri planda kalan aktiviteler } \\
\text { arasındadır. }\end{array}$ & -3 & 0 \\
\hline Başkonuş mesire yeri orman evlerinde konaklamak için uygun ortam sunar. & 0 & 0 \\
\hline $\begin{array}{l}\text { Orman evlerinde konaklama Başkonuş mesire yeri için ön planda olmayan bir } \\
\text { aktivitedir. }\end{array}$ & -2 & -2 \\
\hline Başkonuş mesire yeri doğayı gözlemlemek ve öğrenmek için ortam sunar. & 1 & 2 \\
\hline $\begin{array}{l}\text { Başkonuş'un mesire amaçlı kullanılması, alanın bazı doğal özellikleri için risk } \\
\text { oluşturmaktadır. }\end{array}$ & 4 & 1 \\
\hline
\end{tabular}




\section{Başkonuş Mesire Yeri’nden (Kahramanmaraş) Sağlanan Ekosistem Hizmetlerine Yönelik Algının İncelenmesi}

\begin{tabular}{|c|c|c|}
\hline $\begin{array}{l}\text { Başkonuş mesire yeri yörede yetişen bazı ürünlere ulaşmak için uygun ortam } \\
\text { sunar. }\end{array}$ & -1 & 1 \\
\hline Yöresel ürünlere Başkonuş mesire yerinden başka yerlerde de ulaşılabilir. & 0 & 2 \\
\hline Başkonuş mesire yeri dinlenmek için uygun ortam sunar. & 1 & 4 \\
\hline $\begin{array}{l}\text { Başkonuş mesire yerinin dinlendirici etkisi yöredeki diğer benzer yerler ile } \\
\text { aynıdır. }\end{array}$ & -1 & -3 \\
\hline Başkonuş mesire yeri mevsimleri izlemek ve yaşamak icin uygun ortam sunar. & 1 & 1 \\
\hline $\begin{array}{l}\text { Başkonuş mesire yerinde kullanımlar sonucu oluşan kirlilik ve bakımsızlık } \\
\text { görselliği olumsuz etkiler. }\end{array}$ & 3 & -3 \\
\hline $\begin{array}{l}\text { Başkonuş mesire yeri sanat, edebiyat ve bilim alanında eserler geliştirmek için } \\
\text { ilham verir. }\end{array}$ & 0 & 1 \\
\hline $\begin{array}{l}\text { Başkonuş mesire yerinin bir eser geliştirmek için insana ilham verme potansiyeli } \\
\text { düşüktür. }\end{array}$ & -4 & -1 \\
\hline Başkonuş mesire yeri bölgenin turizm potansiyelini artırır. & 0 & 1 \\
\hline $\begin{array}{l}\text { Başkonuş mesire yerinden başka yörede turistlerin ilgisini çekecek daha güzel } \\
\text { yerler vardır. }\end{array}$ & -1 & -2 \\
\hline $\begin{array}{l}\text { Başkonuş mesire yeri yaşanılan toplumun ve çevrenin bir parçası olma } \\
\text { duygusunun gelişmesine katkı sağlar. }\end{array}$ & -2 & 0 \\
\hline $\begin{array}{l}\text { Çevreye yönelik aidiyet duygusu Başkonuş mesire yeri ile ilgili olmayan bir } \\
\text { konudur. }\end{array}$ & -2 & -2 \\
\hline Başkonuş mesire yeri sosyalleşmek için uygun ortam sunar. & 0 & 0 \\
\hline $\begin{array}{l}\text { Toplumla bir arada olmak için yörede Başkonuş mesire yerinden daha uygun } \\
\text { alanlar vardır. }\end{array}$ & -1 & -2 \\
\hline $\begin{array}{l}\text { Sunulan imkanların zenginliği Başkonuş'un mesire yeri olarak tercih edilmesini } \\
\text { sağlamaktadır. }\end{array}$ & 0 & 1 \\
\hline Başkonuş mesire yerinde tesis ve altyapı olanakları geliştirilmelidir. & 2 & 2 \\
\hline
\end{tabular}

Çizelge 2'de ifadelerin dizgi üzerindeki konumlarına ait bilgiler doğrultusunda her iki faktörün Başkonuş mesire yeri hakkında birleștikleri veya ayrıldıkları konular hakkında da bilgi edinmek mümkündür. Daha önce de belirtildiği üzere Koruma ve Doğallık bakış açılarına sahip faktörleri meydana getiren katılımcilar mesire yerinin oksijen miktarı ve serinletici etkisi üzerine fikir birliği içerisinde olmuşlardır. Buna ek olarak, mesire yerinde tesis ve altyapı olanaklarının geliştirilmesi gerektiğine dair ifade her iki faktörün ortak görüş geliştirdiği konular arasında yer almaktadır $(+2,+2)$. Faktörler aynı zamanda herhangi bir ifadeye katılmayarak da ortak görüş sergileyebilmektedirler. Örneğin, "Orman evlerinde konaklama Başkonuş mesire yeri için ön planda olmayan bir aktivitedir" ifadesine her iki faktörde olumsuz görüş bildirilmektedir (-2, 2). Diğer taraftan, 1 nolu faktörde (Koruma) üzerinde önemle durulan sükûnet, kirlenme ve doğal yapı üzerindeki baskı ile ilgili üç ifade 2 nolu faktörde (Doğallık) aynı düzeyde kabûl görmeyerek her iki faktörün birbirinden ayrıldı $\breve{~} 1$ görüşleri meydana getirmişlerdir. Yine bir diğer örnekte, Başkonuş mesire yerinin biyolojik çeşitliliğe olan katkısına 2 nolu faktörde onay verilirken 1 nolu faktörde aynı ifadeye nispeten olumsuz görüş bildirilmektedir $(-1,+3)$.

\section{Sonuç ve Öneriler}

Bu çalışma ile, Kahramanmaraş İli'nde bulunan ve rahat ulaşım imkânı, zengin bitki örtüsü, elverişli iklimi, konaklama olanakları ve altyapısı ile bölge insanları için önemli bir rekreasyon alternatifi oluşturan Başkonuş mesire yerinin sunduğu ekosistem hizmetlerine yönelik kullanıcı algısının Q metodoloji yardımıyla incelenmesi amaçlanmıştır. 


\section{Başkonuş Mesire Yeri’nden (Kahramanmaraş) Sağlanan Ekosistem Hizmetlerine Yönelik Algının İncelenmesi}

Alan hakkında bilgi ve deneyim sahibi olan, uzmanlar ile diğer eğitim ve meslek gruplarının oluşturduğu katılımcı grubu tarafindan yapılan değerlendirme sonucunda, Başkonuş mesire yerine yönelik iki bakış açısı ortaya çıkmıştır. Bu bakış açılarını ortaya koyan katılımcıların çoğunluğu mesire yerinin yaşam konforu üzerindeki olumlu etkilerini ön plana çıkarmışlar, ancak bununla birlikte, zaman zaman yoğunlaşabilen rekreasyonel faaliyetlerin sükûnet ortamını ve doğal çevreyi olumsuz etkilediğine değinmeyi de ihmal etmemişlerdir. Çalışma ile elde edilen sonuçlar göstermiştir ki, Q metodoloji insanların sahip oldukları bakış açıları altında bir araya getirilmesini, bakış açılarının benzer ve farklı yönlerinin anlaşılmasını, düşüncelerin kendi aralarında önceliklendirilmesini ve genel olarak da toplumda konuya yönelik oluşan farklı fikirlerin ortaya çıkarılmasını sağlayabilen bir yapıya sahiptir.

Çalışma ile elde edilen bulgulardan ve yukarıda yapılan değerlendirmelerden yola çıkılarak, gelecekte yapılacak benzer bilimsel araştırmalara ve Başkonuş mesire yerine yönelik uygulamalara katkı sağlayacak bir dizi öneriler geliştirmek mümkündür:

- Peyzaj planlama ve tasarımı çalışmalarında işlevsel ve sürdürülebilir sonuçlar elde edilmesinde paydaşların karar alma süreçlerine dahil edilmesi önemli bir aşama olup, Q metodolojinin bu amaca ulaşmada etkin bir alternatif olarak kullanılabileceği düşünülmektedir.

- İfadelerin belirlenmesi Q metodoloji çalışmasının başarısında önemli rol oynamakta olup, bu süreçte salt literatüre bağlı kalınmayarak konu hakkında değerlendirme yapabilecek kişilerden de yararlanılması önerilmektedir.

- Bu çalışma, görüşlerin ortaya konulmasında katılımcilarin olumsuz ifadelerden de yararlandıklarını, ve bu durumun, faktörlerin birbirlerinden ayrıldığı noktaları meydana getirecek kadar önem taşıdığını göstermiştir. Buradan hareketle, ifadelerin belirlenmesi sürecinde ifadeler arasında olumsuzların da yer alıyor olmasina dikkat edilmesi tavsiye edilmektedir.
- Bu çalışma ile elde edilen sonuçlar, katılımcıların Başkonuş mesire yerinin insan yaşam konforuna yönelik katkılarının bilincinde olduklarını, bununla birlikte, yoğun kullanımların meydana getirdiği olumsuzluklar bakımından da yüksek farkındalık sergilediklerini göstermektedir. Katılımcilar tarafindan ortaya konulan bu yaklaşımlar, Başkonuş mesire yerinin iyileştirilmesi ve korunması gereken özelliklerine işaret etmesi bakımından önem taşımaktadır. $\mathrm{Bu}$ bağlamda, mesire yeri ziyaretçi taşıma kapasitesinin hesaplanması ve bu hesaplama ile önceki bilimsel çalışmalar doğrultusunda endemik ve nadir taksonlar üzerindeki baskıyı azaltmak üzere rekreasyonel kullanımların sinırlandırılması, yapısal düzenlemelerden olabildiğince kaçınılarak alanın doğal şekli ile kalabilmesi için maksimum özenin gösterilmesi önerilmektedir.

- Katılımcıların Başkonuş mesire yerine yönelik olarak ifadeler aracılığıyla ortaya koydukları görüşleri, aynı zamanda alan ile ilgili yapılabilecek yeni araştırmalara da 1şık tutmaktadır. Örneğin; mesire yerinde kalıcı bir sükûnetin sağlanabilmesi için ne tür önlemler alınabileceği, imkân verilmesi halinde hangi aktivitelerin tercih edilebileceği gibi konuların alanın iyileştirilmesi kapsamında yine Q metodoloji aracılığıyla daha detaylı biçimde ele alınabileceği düşünülmektedir.

\section{Kaynaklar}

Alexander, K. S., Parry, L., Thammavong, P., Sacklokham, S., Pasouvang, S., Gonnell, J. G., Jovanovic, T., Moglia, M., Larson, S., Case, P. (2018) Rice farming systems in Southern Lao PDR: Interpreting farmers' agricultural production decisions using Q methodology. Agr Syst 160:1-10.

Amin, Z. (2000) Q Methodology - A journey into the subjectivity of human mind. Singapore Medic J 41(8):410-414.

Anonim (2011) Başkonuş Orman İşletme Şefliği Fonksiyonel Orman Amenajman Planı (2012-2021) IV. Yenileme, Kahramanmaraş. https://www.ogm.gov.tr/tr/ekutuphane/kit 


\section{Başkonuş Mesire Yeri’nden (Kahramanmaraş) Sağlanan Ekosistem Hizmetlerine Yönelik Algının İncelenmesi}

aplik/egitim-dokumanlari/egitimdokumanlari-oip Erişim 02 Nisan 2021.

Başkonuş Yaylası [@baskonusyaylasi] Instagram Erişim: 23 Nisan 2021.

Breure, A. M., De Deyn, G. B., Dominati, E., Eglin, T., Hedlund, K., Van Orshoven, J., Posthuma, L. (2012) Ecosystem services: a useful concept for soil policy making!, Curr Opin Env Sust 4:578-585.

Brown, S. R. (1980) Political subjectivity: Applications of Q methodology in political science. Yale University Press, New Haven, CT.

Brown, S. R. (1993) A primer on Q methodology. Oper Subj 16(3/4):91-138.

Buchel, S., Frantzeskaki, N. (2015) Citizens' voice: A case study about perceived ecosystem services by urban park users in Rotterdam, the Netherlands. Ecosyst Serv 12:169-177.

Cuppen, E., Breukers, S., Hisschemöller, M., Bergsma, E. (2010) Q methodology to select participants for a stakeholder dialogue on energy options from biomass in the Netherlands. Ecol Econ 69:579591.

Çiftçioğlu, G. C., Aydın, A. (2018) Urban ecosystem services delivered by green open spaces: an example from Nicosia City in North Cyprus. Environ Monit Assess 190: 613.

Çiftçioğlu, G. C. (2020) Using a combination of Q-methodology and survey-based approach for assessing forest ecosystem services of Five Finger Mountains in Northern Cyprus. Sust Sci 15:1789-1805.

De Groot, R., Fisher, B., Christie, M., Aronson, J., Braat, L., Gowdy, J., Haines-Young, R., Maltyby, E., Neuville, A., Polasky, S., Portela, R., Ring, I. (2010a) Integrating the ecological and economic dimensions in biodiversity and ecosystem service valuation, Chapter 1. In The Economics of Ecosystems and Biodiversity: Ecological and Economic Foundations, Ed. G.K. Kadekodi, Earthscan, London and Washington.

De Groot, R. S., Alkemade, R., Braat, L., Hein, L., Willemen, L. (2010b) Challenges in integrating the concept of ecosystem services and values in landscape planning, management and decision making. Ecol Complex 7:260-272.

Demir, F., Kul, M. (2011) Modern Bir Araştırma Yöntemi Q Metodu. Adalet Yayınevi, Ankara.

Gauger, S. E., Wyckoff, J. B. (1973) Aesthetic Preference for Water Resource Projects: An Application of Q Methodology. J Am Water Resour As 9(3):522-528.

Hermans, F., Kok, K., Beers, P. J., Veldkamp, T. (2011) Assessing Sustainability Perspectives in Rural Innovation Projects Using Q-Methodology. Socio Rural 52(1):70-90.

Jobstvogt, N., Townsend, M., Witte, U., Hanley, N. (2014) How can we identify and communicate the ecological value of deep-sea ecosystem services? PloSONE 9(7):e100646.

Karakoç, A., Karabulut, M. (2017) Başkonuş Yaylası. Kahramanmaraş Ansiklopedisi, 2. Cilt, Kahramanmaraş Sütçü İmam Üniversitesi Yayınları No: 146, s. 57-59.

Karasu, M., Peker, M. (2019) Q Yöntemi: Tarihi, Kuramı ve Uygulaması. Türk Psikoloji Yazllarl 22(43):28-39.

Kerr, G. N., Swaffield, S. R. (2012) Identifying cultural service values of a small river in the agricultural landscape of Canterbury, New Zealand, using combined methods. Soci Nat Resour 25:1330-1339.

Koçyiğit, M., Kayıran, S. D. (2018) "Small Protected Areas" for Conservation Priorities in South Anatolia (Başkonuş Mountain-Kahramanmaraş). Eur J Biol 77(2):89-96.

Maniatakou, S., Berg, H., Maneas, G., Daw, T. M. (2020) Unravelling Diverse Values of Ecosystem Services: A Socio-Cultural Valuation Using Q Methodology in Messenia, Greece. Sustain 12, 10320.

Martin-Lopez, B., Iniesta-Arandia, I., GarciaLlorente, M., Palomo, I., CasadoArzuaga, I., Garcia Del Amo, D., GomezBaggethun, E., Oteros-Rozas, E., Palacios-Agundez, I., Willaarts, B., Gonzalez, J. A., Santos-Martin, F., Onaindia, M., Lopez-Santiago, C., Montes, C. (2012) Uncovering Ecosystem 


\section{Başkonuş Mesire Yeri’nden (Kahramanmaraş) Sağlanan Ekosistem Hizmetlerine Yönelik Algının İncelenmesi}

service bundles through social preferences. PLoS ONE 7(6): e38970.

MEA (Millenium Ecosystem Assessment) (2005a) Ecosystems and Human WellBeing: Policy Responses, Vol 3. Eds. Chopra, K., Leemans, R., Kumar, P., Simons, H. Island Press, Washington, DC.

MEA (Millenium Ecosystem Assesment) (2005b) Ecosystem and Human WellBeing: Synthesis. Island Press, Washington, DC.

Niemala, J., Saarela, S. R., Söderman, T., Kopperoinen, L. Yli-Pelkonen, V., Vare S., Kotze, D. J. (2010) Using the ecosystem services approach for better planning and conservation of urban green spaces: a Finland case study. Biodiv Conserv 19:3225-3243.

Pike, K., Wright, P., Wink, B., Fletcher, S. (2015) The assessment of cultural ecosystem services in the marine environment using Q methodology. J Coast Conserv 19:667-675.

Sala, R., Oltra, C., Gonçalves, L. (2015) Attitudes towards urban air pollution: a $\mathrm{Q}$ methodology study / Actitudes frente a la contaminación atmosférica urbana: un estudio basado en el método Q. Psyecology 6(3):359-385.

Sandal, E. K. (2017) Andırın. Kahramanmaraş Ansiklopedisi, 1. Cilt, Kahramanmaraş Sütçü İmam Üniversitesi Yayınları No: 145, s. 293.

Santos-Martin, F., Kelemen, E., Garcia Llorente, M., Jacobs, S., Oteros-Rozas, E., Barton, D. N., Palomo, I., Hevia, V., MartínLópez, B. (2017) Socio-cultural valuation approaches, In: B. Burkhard, J. Maes (Eds.), Mapping ecosystem services.

Schmolck, P. (2014) PQ Method Sosftware, http://schmolck.org/qmethod/ Erişim 17 Mayıs 2020.

Scholte, S. S. K., van Teeffelen, A. J. A., Verburg, P. H. (2015) Integrating sociocultural perspectives into ecosystem service valuation: A review of concepts and methods. Ecol Econ 114:67-78.

Stainton Rogers, R., (1995) Q methodology. In: J.A. Smith, R. Harre, L. Van Langenhove,
(Eds.), Rethinking methods in psychology. Sage, London.

Steelman, T. A., Maguire, L. A. (1999) Understanding participant perspectives: Q-Methodology in national forest management. J Policy Anal Manag 18(3):361-388.

Stephenson, W. (1935). Technique of Factor Analysis. Nature 136:297.

TEEB Foundations (2010) The Economics of Ecosystems and Biodiversity: Ecological and Economic Foundations. Kumar $\mathrm{P}$ (ed), Earthscan, London.

Watts, S., Stenner, P. (2005) Doing Q methodology: theory, method and interpretation. Qualitat Res Psychol 2(1): 67-91.

Webler, T., Danielson, S., Tuler, S. (2009) Using $\mathrm{Q}$ method to reveal social perspectives in environmental research. Greenfield MA: Social and Environmental Research Institute.

https://www.serius.org/pubs/Qprimer.pdf Erişim 30 Nisan 2020.

Varol, Ö. (2003) Flora of Başkonuş Mountain (Kahramanmaraş). Turk J Bot 27:117139.

Yıldırım, İ. (2017) Eğitimin oyunlaştırılmasına ilişkin öğrenci algıları: Bir Q metodu analizi. Eğitim ve Bilim, 42(191):235-246.

Zivojinovic, I., Wolfslehner, B. (2015) Perceptions of urban forestry stakeholders about climate change adaptation - A Qmethod application in Serbia. Urb For Urb Gree 14:1079-1087. 
Başkonuş Mesire Yeri’nden (Kahramanmaraş) Sağlanan Ekosistem Hizmetlerine Yönelik Algının İncelenmesi 